
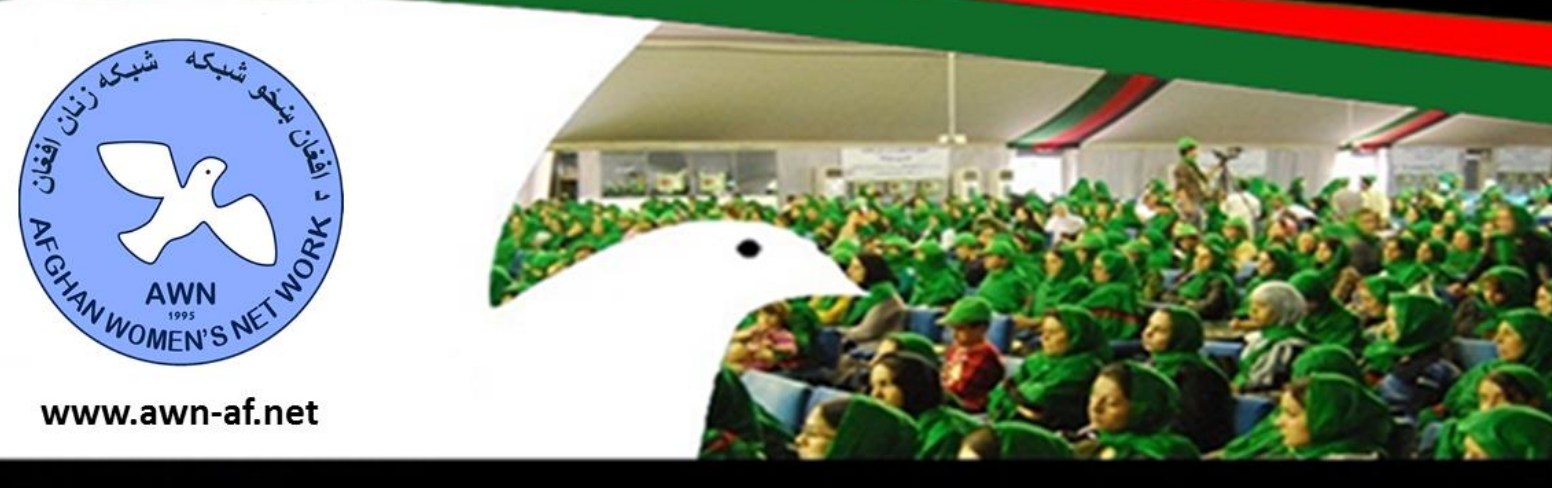

www.awn-af.net

\title{
Afghan Women's Network Capacity Building Program
}

\section{Introduction:}

AWN's Capacity Building Department focuses on building the capacity of Afghan women so that, in the short term, they are able to take active part in improving women's lives and play an important role in the rehabilitation of their country and, in the long term, revive the state institutions.

AWN provides capacity building opportunities to its members and to governmental bodies in the context of technical assistance, awareness raising, exposure visits/travel, and in-country training programs."

Young Women Leadership is one of the major AWN programs in the capacity building, the program is Develop and established for young women's leadership aimed at increasing the representation of qualified young women in governance and political processes. It is also to create sustainable resources that are committed for advancing gender equality in Afghanistan within the political, legislative and social realm of the country. It is envisaged that the women trained through the program will continue to work with, and strengthen, advocacy efforts on women's rights post the program.

STAIDs Project implementing by Afghan Women's Network is aimed to increase the capacity of AWN and it's member organisations through different subjects and approaches, including : Advocacy, Leadership, Participation of women in Peace Process, Violence against women, Harassment of Resolution, UNSCR 1325, CEDAW, Management, Gender, EVAW, TOT, Proposal writing, Report writing, Women right, Child right, Communication, Monitoring and NAPWA and others.

\section{Young Women Leadership Program in last terms :}

Young Women leadership program is designed for the capacity building of the Young leaders which aimed to play active roles in the government and country political ground. The program is financial sponsored by the Australian government (AUSAID) runs in 2 cohorts over two years for period of 10 months each.

Each cohort divided into two sections of 5 months as in the first 5 months, the participants will be trained on different subjects including; leadership development, gender and equality concepts, communication strategies, advocacy and lobbying strategies, political and civil engagement, peace processes, national and international women's rights laws and policies, computer skills, organization and management skills. 
Selection of candidates is through a competitive process as AWN capacity-building department initially developed questioners and conducted training need assessment through face to face interview with member organization's representatives in order to identify and Prioritized the most need Capacity building trainings both for AWN internal and Member organization staff, for the last terms the assessment have conducted within 123 AWN member's organizations located among 25 in provinces and 75 in Kabul.

\section{Achievements}

During the program there were some achievements which is pointed as below:

- $\quad$ Conducting 24 workshops in different topics such as (Advocacy, Security, Violence leadership, Gender. Elimination of violence against women, Harassment of Resolution, Elimination of Valance against women, Harassment of women at workplace Management. Violence NAPWA. UNSCR1325, EVAW, CEDAW, Child custody, Heritage ,Security, for partner agencies, organizational members and internal employers of AWN

- Successful completion of two rounds program of Young Women Leadership according to the work plan

- $\quad$ The participants of Young Women Leadership got the membership of youth union

- $\quad$ YWL participants have the opportunities to have face to face meetings in leadership level and sharing their thoughts and experience with each other

- $\quad$ Some of the YWLP have been interviewed by some TV channels

- Improving the speaking skills of the participants that they can facilitated the programs as announcer

- $\quad$ Five persons from first round and ten persons from second round of YWL program has been hired in different positions in national and international organizations

- Sixty five organizations has been observed and interviewed in a very short period of time

- $\quad$ Developed the material for each training in variety issues

- $\quad$ Developing three manuals (Advocacy. Leadership and Gender)

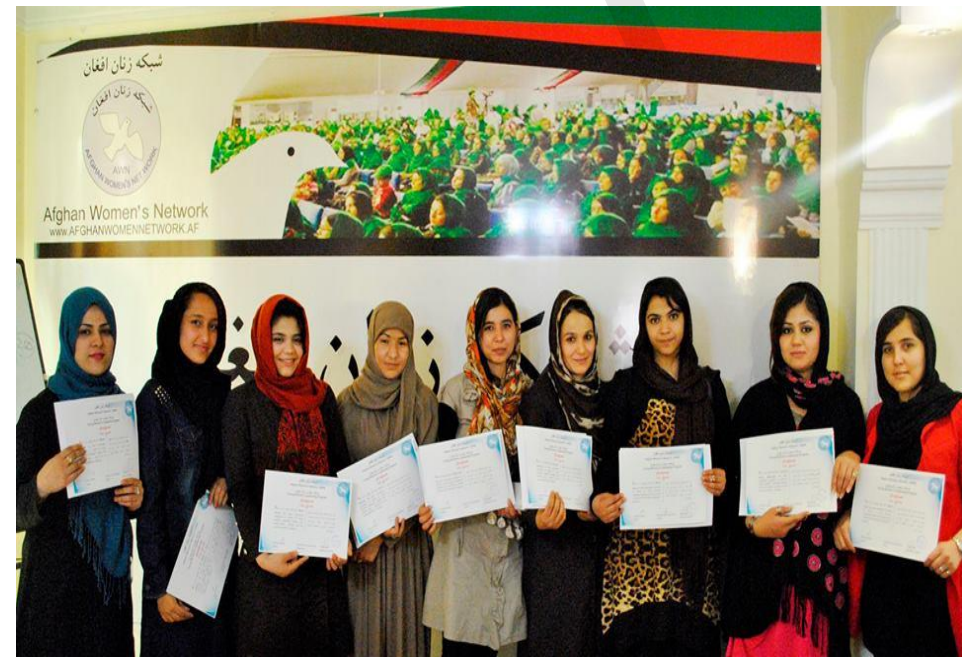

Figure - First Round of YWLP

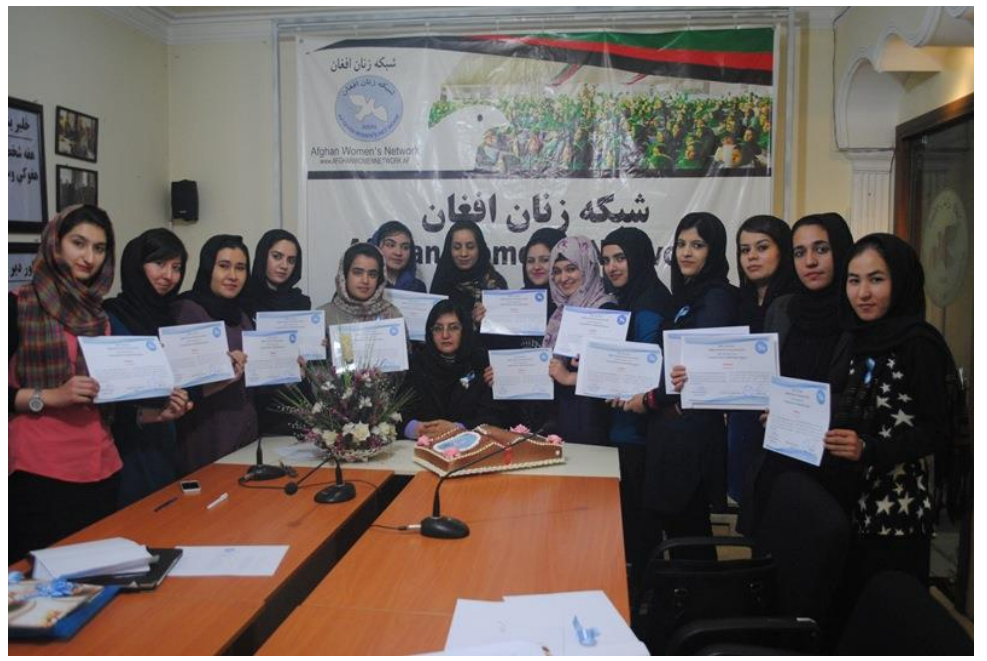

Figure 1- Second Round of YWLP

Prepared By: Muska Meeran 